\title{
PREVALENCE OF THE ORAL HABITS THAT CAUSE ANTERIOR OPEN-BITE IN EGYPTIAN PRE-ADOLESCENTS (CROSS-SECTIONAL STUDY)
}

\author{
Eman M El-Sayed * and Amany Hassan Abdel Ghani**
}

\begin{abstract}
The oral habits were claimed to be among the most causative factors of anterior open-bite (AOB). As AOB is being one of the most difficult cases to orthodontically treat, the proper identification of etiology is important to treat or even prevent the occurrence of the malocclusion. Hence the aim of the study was to identify the oral habits prevalence causing the anterior openbite. 829 malocclusion preadolescents of both sexes were diagnosed, out of which the percentage of anterior open bite was recorded, as well as, the accompanying oral habits and the data were then statistically analyzed. Out of those patients, $20.9 \%$ had AOB. The highest prevalence of habit was the tongue thrust, followed by thumb sucking, mouth breathing and least was lip biting. Some cases showed more than one habit.
\end{abstract}

\section{INTRODUCTION}

Anterior open bite is identified as the lack of over bite between anterior teeth. It could be simple where it is confined to the incisors area, or complex where it extends posteriorly to the premolar and molar regions. ${ }^{(1)}$ An accurate diagnosis and determination of the etiology are always the best guides to establish the objectives and the ideal treatment plan for such a malocclusion. ${ }^{(2,3)}$ Treatment of anterior open bite is one of challenging treatment mechanics. ${ }^{(4-6)}$ Hence, early interception is much preferred by the clinicians.
The etiology of anterior open-bite is multifactorial, but the most common cause is abnormal habits. This includes; digital sucking, mouth breathing, abnormal swallowing and tongue thrust. The prevalence of malocclusion among the school children of both sexes was determined in previous studies. ${ }^{(7-9)}$ The prevalence of anterior openbite among Egyptian population was recorded to be about $6.9 \%$ of the population. ${ }^{(10)}$ But the etiological factors of such malocclusion cases have not been documented and hence the aim of the present study.

\footnotetext{
* Lecturer at the Orthodontic Department, Faculty of Dentistry, Cairo University.

** Assistant Professor at the Orthodontic Department, Faculty of Dentistry, Cairo University.
} 


\section{AIM OF THE STUDY}

The aim the present study was to report the Prevalence of different oral habits that cause anterior open bite among Egyptian pre-adolescents of both sexes.

\section{MATERIAL AND METHODS}

The total diagnosed malocclusion cases: 829; through a six months period, starting from May till end of December 2017 from the outpatient clinic of Orthodontic department, Faculty of Dentistry, Cairo University. Each patient was diagnosed under light illumination using clean sterile gloves and mirror. A diagnostic sheet was filled by examiner regarding patient's age, sex, past and present medical and dental histories and if history of bad oral habit was present. Clinical examination was used to record the presence of anterior open-bite and the existing bad oral habits. The sample ages ranged from 8-12 years. The children were assigned into groups according to the habit causing the AOB. The habits included; thumb sucking, lip biting, mouth breathing and tongue thrusting. The habits were either present at the time of diagnosis or ceased. The participants were free from any syndromes or any systemic diseases.

\section{Statistical analysis}

All Data were collected, tabulated and subjected to statistical analysis. Statistical analysis is performed by SPSS in general (version 16), while Microsoft office Excel is used for data handling and graphical presentation. Variables are described by frequency and percentages. Comparison of two proportions are carried out by $\mathrm{z}$ test. Significance level is considered at $\mathrm{P}<0.05(\mathrm{~S})$, while for $\mathrm{P}<0.01$ is considered highly significant (HS). Two Tailed tests are assumed throughout the analysis for all statistical tests.

\section{RESULTS}

\section{A) Prevalence of anterior open-bite:}

Prevalence of anterior open-bite in preadolescent Egyptians sample as percentage of those having malocclusion, as well as, the causative habits were documented in the present study. The statistical analyses showed that the anterior open-bite was $20.9 \%$ of the total malocclusion cases. The incidence of AOB was equally distributed among both sexes. The participants included 520 females and 309 males.

TABLE (1): Prevalence of anterior open-bite among Egyptian preadolescents.

\begin{tabular}{|l|c|c|c|}
\hline & Males & Females & All \\
\hline $\begin{array}{l}\text { Anterior Open Bite } \\
\text { cases }\end{array}$ & 61 & 113 & 174 \\
\hline $\begin{array}{l}\text { Total diagnosed } \\
\text { malocclusion cases }\end{array}$ & 309 & 520 & 829 \\
\hline Prevalence & $\mathbf{1 9 . 7 4 \%}$ & $\mathbf{2 1 . 7 3 \%}$ & $\mathbf{2 0 . 9 9 \%}$ \\
\hline Z & \multicolumn{2}{|c|}{$\mathbf{1 . 0 6}$} & \\
\hline P-value & \multicolumn{2}{|c|}{$\mathbf{0 . 2 8 7 5}$} & \\
\hline
\end{tabular}

$P \geq 0.05$ Non-significant

\section{B) The frequency and percentage of habits caus- ing anterior open-bite:}

The highest frequently causing habit was found to be the tongue thrust solely, followed by thumb sucking with tongue thrusting, then thumb sucking only, mouth breathing only and then tongue thrusting with lip biting. The least frequency was found when the three habits were found together. 


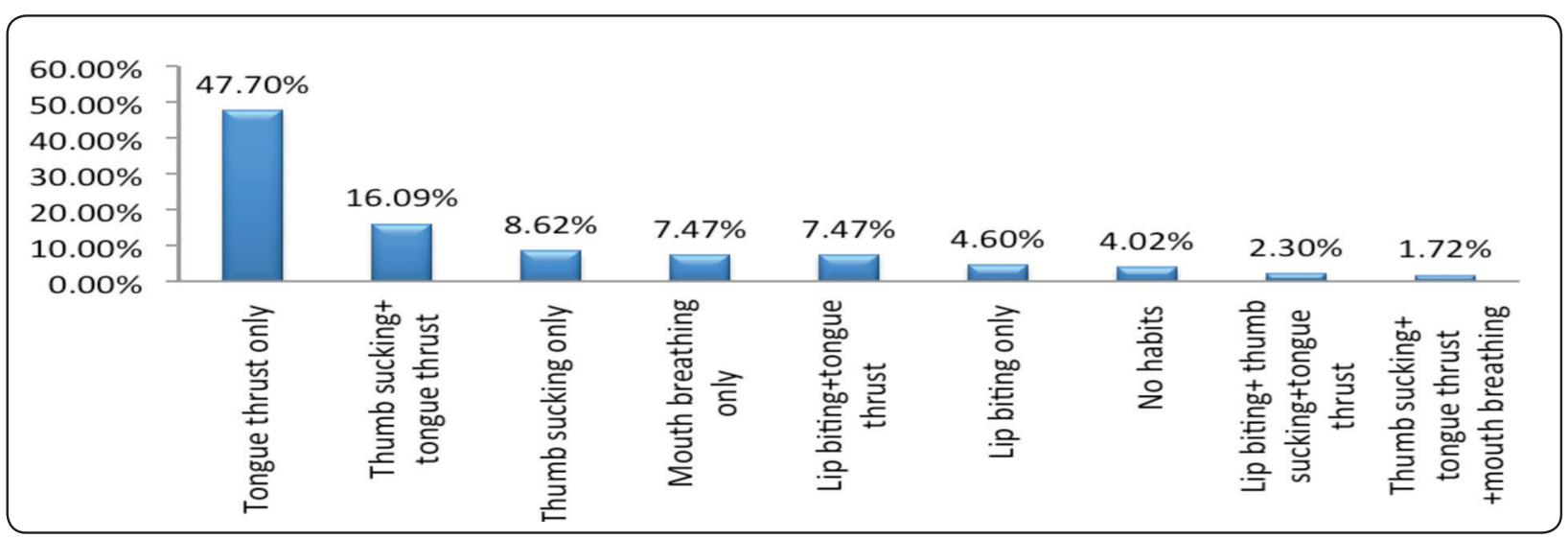

Fig. (1) Percentages of predisposing factors of AOB

TABLE (2): Frequency and percentage of habits causing AOB.

\begin{tabular}{|c|c|c|}
\hline Habit & Frequency & Percentage \\
\hline Tongue thrust only & 83 & $47.70 \%$ \\
\hline Thumb sucking only & 15 & $8.62 \%$ \\
\hline Lip biting only & 8 & $4.60 \%$ \\
\hline Mouth breathing only & 13 & $7.47 \%$ \\
\hline $\begin{array}{c}\text { Lip biting+ thumb } \\
\text { sucking+tongue thrust }\end{array}$ & 7 & $4.02 \%$ \\
\hline $\begin{array}{c}\text { Lip biting+tongue thrust } \\
\text { Thumb sucking+ tongue thrust }\end{array}$ & 28 & $16.09 \%$ \\
\hline $\begin{array}{c}\text { Thumb sucking+ tongue } \\
\text { thrust+mouth breathing }\end{array}$ & 3 & $1.72 \%$ \\
\hline
\end{tabular}

\section{C) Comparison of prevalence of the oral habits causing AOB: (Table 3)}

The most frequent oral habit causing AOB was tongue thrust, its prevalence was highly significantly more than the other habits. The thumb sucking, mouth breathing and lip biting did not show any significant difference between them.
TABLE (3): Comparison of oral habits causing anterior open-bite

\begin{tabular}{|c|c|c|}
\hline Oral habits & $\mathbf{Z}$ & p- value \\
\hline $\begin{array}{c}\text { Tongue thrust versus } \\
\text { Lip biting }\end{array}$ & 9.15 & $0.0000^{*}$ \\
\hline $\begin{array}{c}\text { Tongue thrust versus } \\
\text { Thumb sucking }\end{array}$ & 8.10 & $0.0000^{*}$ \\
\hline $\begin{array}{c}\text { Tongue thrust versus } \\
\text { Mouth breathing }\end{array}$ & 8.40 & $0.0000^{*}$ \\
\hline $\begin{array}{c}\text { Thumb sucking only versus } \\
\text { Mouth breathing only }\end{array}$ & 0.39 & 0.6935 \\
\hline $\begin{array}{c}\text { Thumb sucking only versus } \\
\text { Lip biting only }\end{array}$ & 1.51 & 0.1310 \\
\hline $\begin{array}{c}\text { Mouth breathing only versus } \\
\text { Lip biting only }\end{array}$ & 1.13 & 0.2603 \\
\hline
\end{tabular}

*High significant difference when $p$ value is $<0.005$

\section{D) Frequency of appearance of the oral habits:}

The frequency of appearance of the oral habits either alone or combined with other habits showed that the tongue thrust appeared in $75.29 \%$, followed by thumb sucking; $28.74 \%$, lip biting; $14.37 \%$ and the least was mouth breathing; $9.20 \%$. 


\section{DISCUSSION}

The World Health Organization considered the malocclusion as the third priority among oral problems. ${ }^{(6)}$ Consequently, the researchers gained more interest in seeking the environmental causative factors of malocclusion. The oral habits are considered as risk factors, as they cause change in the physiologic balance of growth..$^{(2,7,11-}$ 13) The present study was carried out to clarify the etiology of anterior open-bite diagnosed among the pre-adolescents. The choice of the anterior openbite specially to be studied, because this type of malocclusion is one the most difficult orthodontic cases to be treated, especially at older ages and the high relapse of orthodontic treatment had been reported, even in orthognathic surgeries. ${ }^{(4,8)}$

The study included both sexes who came to seek orthodontic treatment, at the Orthodontic department, Faculty of Dentistry, Cairo University. Out of the total malocclusion cases diagnosed; 829 cases, about $21 \%$ had anterior open-bite, but the extent of open-bite was not identified in the study, as we focused more on the habits' prevalence. No difference was found between both sexes, and this was claimed by previous studies. In previous research studies, prevalence of anterior open-bite (AOB) varied according to demographic factors from $25 \%$ to $38 \%$ of malocclusion cases. A study was performed on Egyptian population showed that AOB was $6.9 \%$ of the sample. The difference here was the percentage in our study was out of malocclusion cases, while that of Aburayaan et al. was among normal together with malocclusion cases. ${ }^{(10)}$ The anterior open-bite identified in the study varied from moderate (grade 3) to high risk (grade 4), according to the ROMA index. ${ }^{(14)}$ The Nigerian population showed $2.8 \%$ of AOB, Swedish population; $3.7 \%$ of AOB, British; $8.4 \%$, and Portuguese; $11.3 \% .^{(3-6)}$ Albanese population showed AOB to constitute $80 \%$ of the malocclusion cases. ${ }^{(6)}$ Non-significant difference was found between the two sexes in the present study, which was in-accordance to that found by the previous studies, ${ }^{(7,12-15)}$ while others found AOB was more prevalent among females..$^{(9,17-19)}$

The oral habits that caused anterior open-bite was documented in this study to be either one single habit or several habits at a time. The most prevalent habit was the type of a single one, and rarely was the cause found to be multi-habitual. Cozza found that the sucking habits significantly increased the AOB by 4 times. ${ }^{(21)}$

A very small percentage of the patients; about $4 \%$ had no habits preceding the anterior openbite, while $96 \%$ of them were preceded by oral habits. Those habits varied from, tongue thrust that represented the highest percentage among the habits; $47.7 \%$. This was followed by the tongue thrusting and thumb sucking habit together; $16 \%$, then thumb sucking only; $8.6 \%$, mouth breathing only and lip biting with tongue thrusting; each represented $7.47 \%$ of the total habits. The lip biting only caused anterior open-bite in about $4.6 \%$ of the case. The lowest percentage of habits found were more than one habit evoking the malocclusion; lip biting with thumb sucking and tongue thrusting; $2.3 \%$ and thumb sucking with tongue thrusting and mouth breathing; $1.7 \%$. The difference between the tongue thrust and each of the single causing habit; thumb sucking, mouth breathing or lip biting was highly significant.

Tongue thrust habit could be reciprocal, as it might cause malocclusion or be as a consequence of malocclusion. This might explain the highest prevalence of this habit in $\mathrm{AOB}$, where it be causative or adaptive to the already existing AOB. The tongue thrust condition occurs, where the tongue touches anterior teeth during swallowing. Dixit UB stated that the habit is accompanied by, proclined maxillary incisors, hyperactive mentalis muscle and open-bite. ${ }^{(22,23)}$ 
Thumb sucking has been documented to be among the most prevalent causative factors of AOB. ${ }^{(12,16,19,24)}$ It causes a change in the balance between the outward thrust of the tongue on the palate and the inward activity of the check muscle on the maxilla, together with backward rotation of the mandible, leading to anterior open-bite.

Mouth breathing occurs due to hypertrophy of adenoids or tonsils, or any other diseases of nasal airway leading to imbalance of the oral and perioral muscles. Accordingly, clockwise mandibular rotation occurs, leading to anterior open-bite. (2,6-9,17) $^{-1}$ Biting of the lower lip was claimed to lead to strong contraction of the lower lip and mentalis muscle, with excessive maxillary incisors proclination and retroclination of the lower ones, with anterior openbite. ${ }^{(3,25)}$ The AOB associated with more than one habit could be explained that one habit could be causative and the others be a contributed and be adaptation of physiological functions to the existing anterior open-bite.

The high percentage of oral habits in the present study causing anterior open-bite should be an alarm of how destructive those habits could be. Accordingly, the health specialists, pediatricians and parents should be aware of those results and the teaching of the different habit breaking appliances to dental students is a must. It is recommended that this study be performed on larger sample size to clarify why the tongue thrust is the most prevalent among the habits causing the anterior open-bite.

\section{CONCLUSIONS}

1) The bad oral habits provoked $96 \%$ of the etiological causes of anterior open-bite.

2) Tongue thrust habit constituted the highest risk factor, followed by thumb sucking, mouth breathing, then lip biting.

3) Several habitual causes of AOB were found at a time in some cases.

\section{REFERENCES}

1. M. A. N. Matsumoto, F. L. Romano, J. T. L. Ferreira, and R.A. Valério, Open bite: diagnosis, treatment and stability, Braz. Dent. J., vol. 23, no. 6, pp. 768-778, 2012.

2. P. Ngan and H. W. Fields, "Open bite: a review of etiology and management.," Pediatr. Dent., vol. 19, no. 2, pp. 91-8, 1997.

3. R. V. de Sousa et al., "Prevalence and Associated Factors for the Development of Anterior Open Bite and Posterior Crossbite in the Primary Dentition," Braz. Dent. J., vol. 25, no. 4, pp. 336-342, 2014.

4. L.-H. Lin, G.-W. Huang, and C.-S. Chen, "Etiology and Treatment Modalities of Anterior Open Bite Malocclusion," J. Exp. Clin. Med., vol. 5, no. 1, pp. 1-4, Feb. 2013.

5. U. Marmaite et al., "The Prevalence of Malocclusion and Oral Habits among 5-7-Year-Old Children," Med. Sci. Monit., vol. 20, pp. 2036-2042, Oct. 2014.

6. R. J. Kamdar and I. Al-Shahrani, "Damaging oral habits.," J. Int. oral Heal. JIOH, vol. 7, no. 4, pp. 85-7, Apr. 2015.

7. V. Urzal, A. C. Braga, and A. P. Ferreira, "Oral habits as risk factors for anterior open bite in the deciduous and mixed dentition - cross-sectional study.," Eur. J. Paediatr. Dent., vol. 14, no. 4, pp. 299-302, Dec. 2013.

8. C. Van Dyck et al., "The effect of orofacial myofunctional treatment in children with anterior open bite and tongue dysfunction: a pilot study," Eur. J. Orthod., vol. 38, no. 3, pp. 227-234, Jun. 2016.

9. A. Silvestrini-Biavati, S. Salamone, F. Silvestrini-Biavati, P. Agostino, and A. Ugolini, "Anterior open-bite and sucking habits in Italian preschool children.," Eur. J. Paediatr. Dent., vol. 17, no. 1, pp. 43-6, Mar. 2016.

10. A. H. Abdallah A, Eid F, Abdou Sayed F, "Prevalence of malocclusion and orthodontic treatment need in Egyptian school-children (Giza Governorate) A survey study," 2015.

11. M. C. Gomes, É. T. B. Neves, M. F. Perazzo, C. C. Martins, S. M. Paiva, and A. F. Granville-Garcia, Association between psychological factors, socio-demographic conditions, oral habits and anterior open bite in five-yearold children,Acta Odontol. Scand., vol. 76, no. 8, pp. 553558, Nov. 2018.

12. C. Rijpstra and J. A. Lisson, "Etiology of anterior open bite: a review," J. Orofac. Orthop. / Fortschritte der Kieferorthopädie, vol. 77, no. 4, pp. 281-286, Jul. 2016. 
13. M. V. Heimer, C. R. Tornisiello Katz, and A. Rosenblatt, "Non-nutritive sucking habits, dental malocclusions, and facial morphology in Brazilian children: a longitudinal study," Eur. J. Orthod., vol. 30, no. 6, pp. 580-585, Dec. 2008.

14. C. Grippaudo, E.G. Paolantonio, G. Antonini, R. Saulle, G. La Torre, and R. Deli, "Association between oral habits, mouth breathing and malocclusion", Acta Otorhinolaryngol. Ital., vol. 36, no. 5, pp. 386-394, Oct. 2016.

15. I. Ize-Iyamu and M. Isiekwe, "Prevalence and factors associated with anterior open bite in 2 to 5 year old children in Benin city, Nigeria," Afr. Health Sci., vol. 12, no. 4, pp. 446-451, Feb. 2013.

16. A. K. M. Teixeira, J. L. F. Antunes, and L. R. A. Noro, "Factors associated with malocclusion in youth in a municipality of Northeastern Brazil," Rev. Bras. Epidemiol., vol. 19, no. 3, pp. 621-631, Sep. 2016.

17. V. Urzal, A. C. Braga, and A. P. Ferreira, "The prevalence of anterior open bite in Portuguese children during deciduous and mixed dentition - Correlations for a prevention strategy," Int. Orthod., vol. 11, no. 1, pp. 93103, Mar. 2013.

18. S. Machado, M. Manzanares-Cespedes, J. FerreiraMoreira, J. Ferreira-Pacheco, P. Rompante, and J. UstrellTorrent, "A sample of non-nutritive sucking habits (pacifier and digit) in portuguese children and its relation with the molar classes of angle," J. Clin. Exp. Dent., vol. 10, no. 12, pp. e1161-e1166, Dec. 2018.
19. A. Caprioglio and R. Fastuca, "Étiologie et traitements des béances antérieures chez les patients en croissance : une étude narrative," L'Orthodontie Française, vol. 87, no. 4, pp. 467-477, Dec. 2016.

20. L. Stojanović, "[Etiological aspects of anterior open bite].," Med. Pregl., vol. 60, no. 3-4, pp. 151-5.

21. P. Cozza, T. Baccetti, L. Franchi, M. Mucedero, and A. Polimeni, "Sucking habits and facial hyperdivergency as risk factors for anterior open bite in the mixed dentition," Am. J. Orthod. Dentofac. Orthop., vol. 128, no. 4, pp. 517519, Oct. 2005.

22. M. Kawamura, K. Nojima, Y. Nishii, and H. Yamaguchi, "A cineradiographic study of deglutitive tongue movement in patients with anterior open bite.," Bull. Tokyo Dent. Coll., vol. 44, no. 3, pp. 133-9, Aug. 2003.

23. G. M. Lopes-Freire, A. B. C. Cárdenas, J. E. E. Suarez de Deza, J. M. Ustrell-Torrent, L. B. Oliveira, and J. R. Boj Quesada JR, Exploring the association between feeding habits, non-nutritive sucking habits, and malocclusions in the deciduous dentition, Prog. Orthod., vol. 16, no. 1, p. 43, Dec. 2015.

24. V. Luzzi et al., "Malocclusions and non-nutritive sucking habits: a preliminary study," Prog. Orthod., vol. 12, no. 2, pp. 114-118, Nov. 2011.

25. K. Fukumitsu, F. Ohno, and T. Ohno, "Lip sucking and lip biting in the primary dentition: two cases treated with a morphological approach combined with lip exercises and habituation.," Int. J. Orofacial Myology, vol. 29, pp. 42-57, Nov. 2003. 